http://jmscr.igmpublication.org/home/ ISSN (e)-2347-176x ISSN (p) 2455-0450

crossref DOI: https://dx.doi.org/10.18535/jmscr/v8i6.42

\author{
Journal Of Medical Science And Clinical Research \\ IGM Publication \\ An official Publication of IGM Publication
}

\title{
Singhs Index Assessment in Patients Having Sustained Hip Fractures
}

Authors

\section{Dr Ramanujam $\mathbf{P}^{\mathbf{1}}$, Dr Sabarisree. $\mathbf{M}^{2^{*}}$}

${ }^{1}$ Associate Professor (CAP), in Orthopaedics, Government Medical College, Thiruvananthapuram

${ }^{2}$ Additional Professor in Orthopaedics, Government Medical College, Thiruvananthapuram

*Corresponding Author

\section{Dr Sabarisree.M}

Additional Professor in Orthopaedics, Government Medical College, Thiruvananthapuram, India

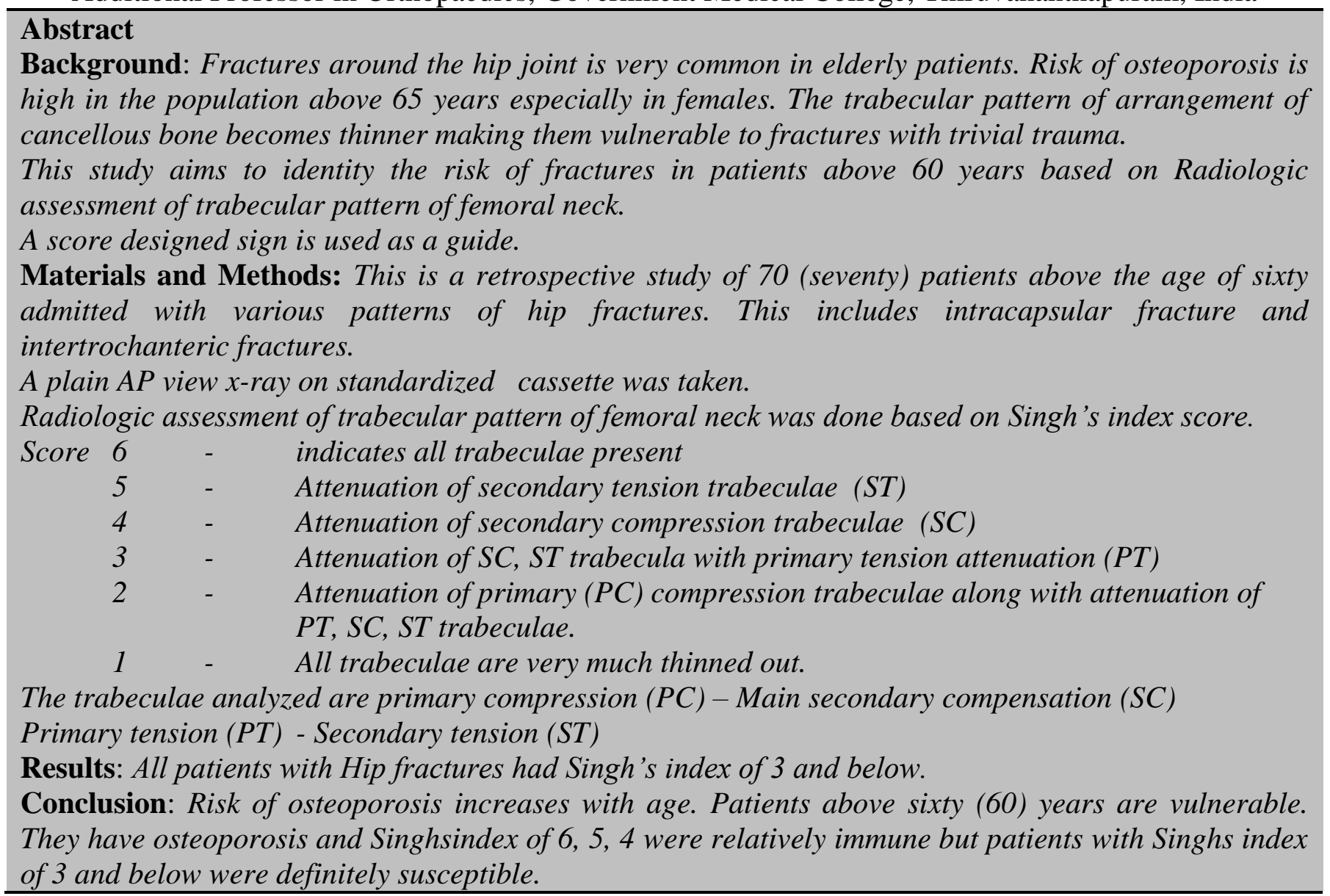

\section{Introduction}

Trabecular pattern of femoral neck is a unique arrangement of bony trabeculae. This is excellent design by nature to enable weight bearing. The prominent trabeculae are
1. Primary compression (PC)- Main trabecular pattern found in the postero medial aspect of femoral neck also called calcar strongest and that to be affected. 
2. Primary tension (PT) trabeculae on superior aspect of neck.

3. Secondary compression SC

4. Secondary tension $-\mathrm{ST}$

At last two patterns are found more in the per trochanteric region they are the first to be affected in osteoporosis.

\section{Objectives}

1. To assess the Singhs index in patients with Hip fractures.

2. To identity if a two score of Singh's Index co-relates with such fractures.

\section{Materials and Methods}

Elderly patients admitted in the orthopaedic wards of government medical college, Trivandrum during period of 2019 (May) - 2020 (May) These patients both male and female had sustained neck of femur and inter trochanteric fractures.

Standard plain X-ray A.P (Anteroposterior) view showing both Hip joints were taken.

\section{Inclusion Criteria}

1. All patients with Hip fractures above sixty years.

\section{Exclusion Criteria}

1. Pathological fractures in elderly

2. Fracture as a result of polytrauma

\section{Results}

A total of seventy patients 58 analyzed were females (80\%). 67 patients had Singh's index of 3 and below (95\%)

Only 3 patients had a grade of 4 .

20 patients were in age group of 60-70 yrs and the score was 3. 25 patients were in the group of 7080 years. The Singh's score was 2.16 patients were in the group of 80-90 years score was again 2. 6 (six) patients were in the age group of 90-100 years. Their score was 1 patient with intra capsular fracture had scores of 2 or 3.
Patients with score of 1 and 2 tended to have more intertrochanteric fractures.

Total of 12 male patients, 10 had score of 3 and only two patients had score of 2 .

This indicates as age advances attenuation of femoral trabeculae are more prominent. Females were more susceptible. A low Singhs score is definitely associated with fractures around Hip.

Total patients -70

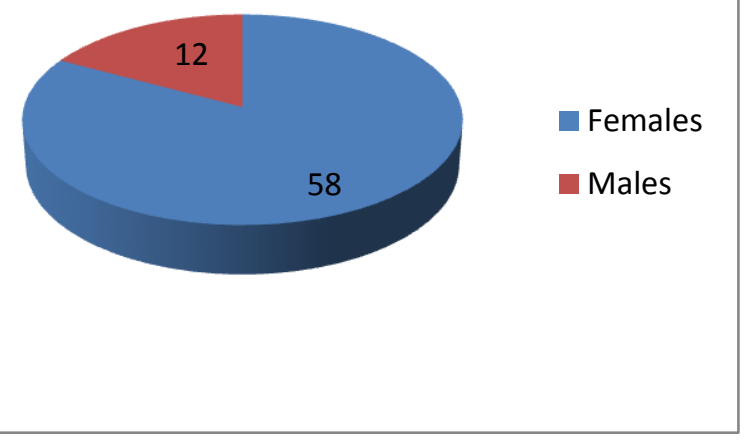

Score Distribution

\begin{tabular}{|l|c|}
\hline Score & No \\
\hline 6 & 0 \\
\hline 5 & 0 \\
\hline 4 & 3 \\
\hline 3 & 20 \\
\hline 2 & 41 \\
\hline 1 & 6 \\
\hline Total & 70 \\
\hline
\end{tabular}

Type of fracture

\begin{tabular}{|l|l|}
\hline Intracapsular fractures & 40 \\
\hline Intertrochanteric & 30 \\
\hline
\end{tabular}

\section{Intracapsular fractures}

Singh's score

\begin{tabular}{|l|c|}
\hline 3 & 20 \\
\hline 2 & 19 \\
\hline 1 & 1 \\
\hline Total & 40 \\
\hline
\end{tabular}

\section{Inter trochanteric fractures}

\section{Singh's score}

\begin{tabular}{|c|c|}
\hline 3 & 5 \\
\hline 2 & 20 \\
\hline 1 & 56 \\
\hline
\end{tabular}




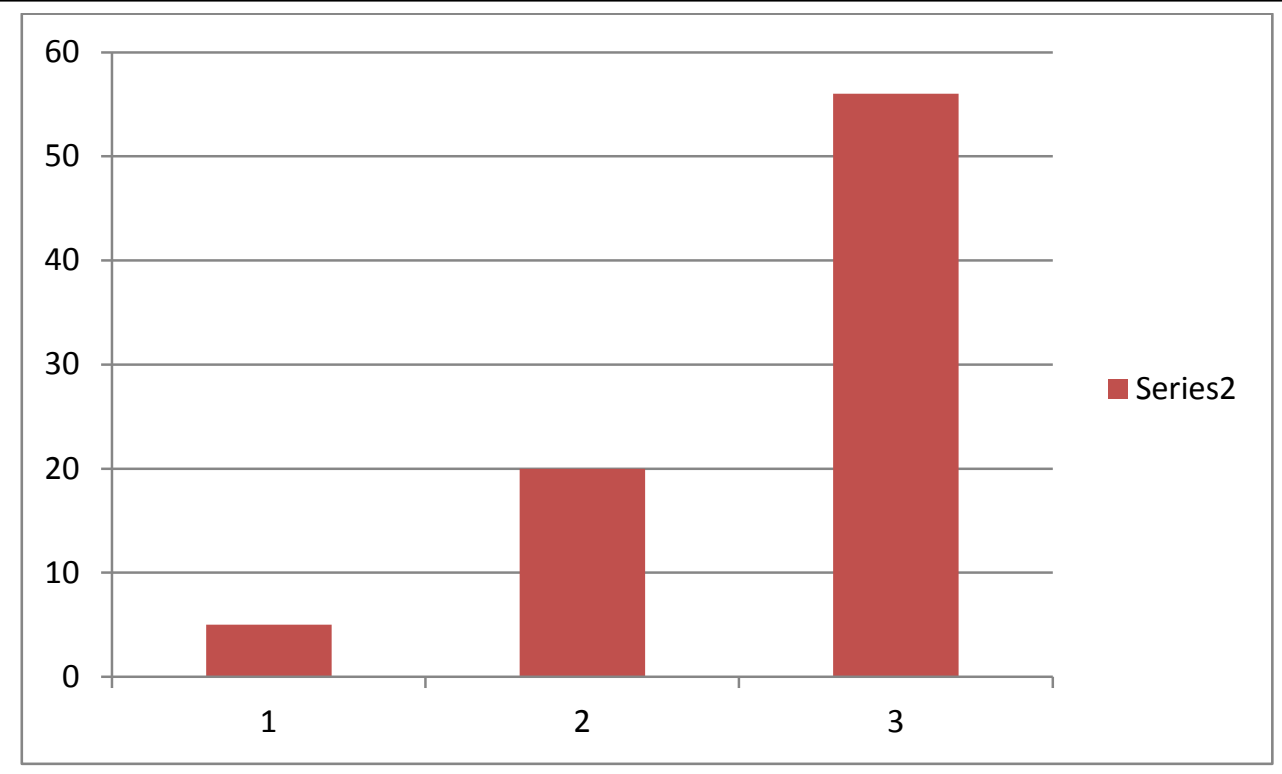

\section{Discussion}

Age related attenuation or thinning of trabecular pattern is evident by Singh's index assessment. It is a rough guide to quantity the degree of osteoporosis. This gives an estimate of extent of osteoporosis which leads to such fractures. Lower the score and higher the age especially female sex were the patients most susceptible.

\section{Conclusion}

Female patients in the age of $70-80$ years were most susceptible to fractures. A score of 3 and below associated with advancing age are poor prognostic factors.

It also indicates a risk of refracture but this study cannot determine which type of fracture a low Singh score patient will sustain.

\section{References}

1. Singh. M. Maini. P.S. -Changes in trabecular pattern of upper end of femur as an idea of osteoporosis JBJS-1970.

2. Krishak, Augat. $\mathrm{P}, \mathrm{Kin} 21$, predictive value of bone mineral density and Singhs index for mechanical properties of cancellous bone in Femoral Head. Journal of Clinical Biomechanics -1999.
3. Soontrapa.S. Modified Singhs index in diagnosing femoral neck osteoporosis 2011, (Pubmed).

4. Patel. S.H. Murphy. K. P. Fracture of proximal femur correlates of radiological evidence of Osteoporosis 2006-(Pubmed).

5. Hauschild, Obsert. M. Evaluation of Singhs index for assessment of osteoporosis using digital radiography 2009 (Pubmed).

6. Yamamoto.M-insights into bone fragility in Diabetes, crucial role of bone qualityon skeletal strength 2015 (Pubmed). 